\title{
Enfermería: del arte a la ciencia o de la ciencia al arte
}

\author{
Fernando Trejo Martínez*
}

\begin{abstract}
RESUMEN
Se realizó un análisis de la ciencia y el arte de la enfermería, en el que se trata de precisar qué es ciencia y qué es arte, para poder establecer las connotaciones de estas definiciones en el terreno disciplinar, para que de esta manera los profesionales de enfermería se formen un criterio propio y puedan expresar una definición particular de la ciencia y el arte de la enfermería; se abordaron también los patrones del conocimiento en enfermería descritos por Carper para ampliar la visión y sustento en la cual el arte de enfermería es el grado máximo del cuidado.
\end{abstract}

Palabras clave: Arte de enfermería, ciencia de enfermería, patrones del conocimiento en enfermería.

\section{Nursing: from art to science or science to art}

\begin{abstract}
We performed an analysis of the science and art of nursing, which seeks to clarify that it is science and art, to establish the connotations of these definitions in the field of discipline, so that in this way nurses are form their own criteria, and can express a particular definition of science and art of nursing, also addressed the patterns of nursing knowledge described by Carper to expand the vision and support in which the art of nursing is the maximum degree care.
\end{abstract}

Key words: Art of nursing, nursing science, nursing knowledge patterns.

$\mathrm{T}$ Tratar de definir la enfermería como un arte o una ciencia parecería complicado; no obstante, con los avances y el desarrollo científico en el campo disciplinar logrados en la segunda mitad del siglo XX y la primera década del XXI, ${ }^{1}$ cualquiera se inclinaría por limitarla como una ciencia, aunque es verdad que para muchos este criterio estaría equivocado ya que también se considera como un arte. Para este autor, ambos están en lo correcto y ambos están equivocados.

Primero se tendría que definir qué es ciencia y qué es arte, después se tendría que enfocar al pensamiento enfermero para luego analizar de forma incluyente todos los conceptos y así llegar a una conclusión que clarifique este enigma.
Por consiguiente, ciencia, puntualiza Bunge, es "un cuerpo creciente de ideas que puede caracterizarse como conocimiento racional, sistemático, exacto, verificable y fiable, que se alcanza por medio de la investigación científica"; así mismo, la Real Academia Española la define como el "conjunto de conocimientos obtenidos mediante la observación y el razonamiento, sistemáticamente estructurados y de los que se deducen principios y leyes generales". ${ }^{3}$ Por otra parte, el Diccionario de Filosofía de Abbagnano describe que es un "conocimiento que incluye de cualquier modo o medida una garantía de la propia validez". ${ }^{4}$

Así mismo Blauberg, en el Diccionario de Filosofía, refiere que es la "esfera de la actividad humana, tiene por

* Maestría en Enfermería en Educación, Instituto Nacional de Neurología y Neurocirugía.

Correspondencia: Fernando Trejo Martínez, Insurgentes Sur Núm. 3877, Colonia La Fama, Delegación Tlalpan, 14269, México, D. F.

E-mail:fertre001@yahoo.com.mx

Este artículo puede ser consultado en versión completa en http://www.medigraphic.com/enfermerianeurologica 
meta estudiar los objetos y fenómenos de la naturaleza, la sociedad y el pensamiento, así como sus propiedades, relaciones y leyes". 5

Cada definición tiene una visión muy particular; sin embargo, las dos primeras se orientan hacia el método científico como el elemento creador y comprobador del conocimiento, mientras que las filosóficas incluyen lo humano y el pensamiento, se refieren más al ser que al hacer; no obstante, las cuatro definiciones tienen algo en común, todas se refieren a ciencia como sinónimo de conocimiento, llevan implícito su método de estudio, abarcan una dimensión que tiene que ver con el ser humano y su forma de concebir el mundo que lo rodea para adjudicarse la esencia de su entorno, asimilarlo y darle un sentido a su estadía.

De esta forma todos los puntos de vista adquieren un elemento en común, la validez de lo que se conoce por ciencia o conocimiento; por lo tanto, ciencia es igual a conocimiento, por ser racional y sistemático, considerando que tiene un método para obtenerlo, por conocimiento tangible y comprobable o por conocimiento del ser y la sociedad, no tan tangible, pero igual de válido.

Concibiendo qué es la ciencia, es pertinente de igual manera tratar de explicar qué es un arte; según la Real Academia Española en su Diccionario de la Lengua Española, es la "virtud, disposición y habilidad para hacer algo", aunque también tiene otros dos conceptos: "manifestación de la actividad humana mediante la cual se expresa una visión personal y desinteresada que interpreta lo real o imaginado con recursos plásticos, lingüísticos o sonoros", también es considerada como un "conjunto de preceptos y reglas necesarios para hacer algo bien". ${ }^{6}$ Sin embargo, el Diccionario Enciclopédico Norma, ${ }^{7}$ y la Enciclopedia Temática Universal editada por Océano ${ }^{8}$ coinciden casi exactamente con lo mencionado por la Real Academia Española, es el "conjunto de preceptos...para hacer algo bien".

Como es de esperarse, las concepciones de los diccionarios filosóficos interpretan de una manera muy singular el término arte, ya que le dan una dimensión estética que implica la belleza; así lo describe Blauberg: "actividad creadora en cuyo proceso se elaboran imágenes artísticas, es decir imágenes concreto-sensoriales que reflejan la realidad y personifican una actitud estética del hombre hacia ella"; para Abbagnano es el arte pero también es "todo conjunto de reglas idóneas para dirigir una actividad humana cualquiera"; este último cita a Platón, quien declara que "no existe una diferencia entre arte y ciencia", debido a que para Platón "arte, es el arte del razonamiento". 10

Frase que tiene una gran profundidad y que de alguna manera implica las dos definiciones, arte y ciencia en una sola oración, deja entrever que primero es el arte y luego el razonamiento entendiéndose como ciencia. Al igual que el concepto de ciencia, arte tiene dos dimensiones, una se enfoca al hacer, o sea todos los elementos que son necesarios para hacer algo bien, y la dimensión por la que se identifica el concepto, haciendo referencia a lo estético, a lo plástico que el ser humano hace para expresar a su manera el entorno en que vive.

Da la impresión que lejos de esclarecer los conceptos, éstos se entremezclan y es precisamente esta ambivalencia la que acentúa el dilema para tratar de aclarar la diferencia entre éstos y poder determinar si enfermería evoluciona del arte a la ciencia, o viceversa.

Así mismo, la ciencia enfermera ha evolucionado de una forma significativa, han surgido teorías y teóricas de manera importante a lo largo del siglo pasado, todas ellas con visiones diferentes pero enfocadas al cuidado de la persona; basta con darle una mirada a las obras de Marriner \& Alligud ${ }^{11} \mathrm{y}$ Riel-Sisca ${ }^{12}$ para constatar el gran desarrollo científico que la disciplina ha tenido.

No obstante, muchos de los profesionales que se formaron en la década de los 80 y 90 , antes de que en nuestro país se diera el cambio del plan de estudios que abarca las teorías y modelos, han tenido recelo para adoptar el proceso enfermero como su modelo para realizar la práctica clínica. Por otra parte las pensadoras enfermeras han evidenciado que la ciencia en enfermería se ha ido construyendo poco a poco, desde mediados del siglo XIX, y se ha consolidado a partir de la segunda mitad del siglo XX $:^{13}$ sin embargo, ha seguido una evolución constante que le ha permitido situarse entre las disciplinas que han logrado cimentar su actuar, basado en un cuerpo propio de conocimientos.

Durán de Villalobos menciona: "la historia del desarrollo... teórico permite entender dentro de un contexto universal, el porqué de sus situaciones... teóricas", y cita a Meleis, que refiere: "la enfermería ha atravesado por diferentes etapas en la búsqueda de identidad profesional y autenticidad, cada una ha servido para dar forma a la siguiente y además ha clarificado las dimensiones necesarias para el establecimiento científico de la disciplina". ${ }^{14}$

No obstante, muchos de sus preceptos son de conocimientos surgidos de otras ciencias. ${ }^{15}$ De manera que al tratar de explicar la complejidad del ser humano ha tomado marcos teóricos de disciplinas afines, pero que explican el comportamiento humano y lo asimila o complementa para fundamentar su quehacer creando una base amplia de conocimientos centrados en el cuidado, que es el eje rector de la ciencia enfermera.

Por otra parte la práctica de enfermería antes del surgimiento de las teorías y del proceso enfermero, estaba dictada por la imitación y la asimilación del "cómo" más que el "porqué, lo que hacía la práctica monótona y arcaica, sin desarrollo y actividades derivadas de la tradición. ${ }^{16}$ 
En el marco de las observaciones anteriores, la práctica clínica es donde se evidencian la ciencia y el arte de enfermería; Carper argumenta cómo el cuerpo de conocimientos da soporte a la enfermería y se manifiesta por patrones, o sea por medio de formas características de expresión externa e interna que dejan ver la manera como se piensa sobre un fenómeno. Los patrones no aumentan el conocimiento, más bien ponen su atención en el significado de conocer y establecer diferentes clases de conocimiento que son de mayor ayuda para la disciplina de enfermería. ${ }^{17}$ Refiere a Weidenbach, quien explica que "el arte de enfermería se hace visible a través de las medidas adoptadas para proporcionar todo lo que el paciente requiere para restaurar o ampliar su capacidad para hacer frente a las demandas de su situación".

En ese mismo sentido, para Carper el arte de enfermería fusiona los patrones de conocimiento ${ }^{18} \mathrm{y}$ hace que la teoría se vincule a la praxis enfermera, dándole un carácter profesional al quehacer disciplinar de enfermería, pero al mismo tiempo le proporciona sentido humanístico, característica primordial del cuidado.

Debido a que al brindar un cuidado, éste debe de ser pertinente en el momento oportuno para satisfacer la demanda que la persona solicita en ese preciso instante, y de esta manera sea posible resolver un problema que requiere del conocimiento empírico, dando solución a dudas que inquieten al enfermo, o sólo el acompañamiento que demanda de nuestra persona para brindar seguridad en algún procedimiento médico, o con la simple presencia para charlar de persona a persona.

El arte de enfermería es el grado máximo del cuidado cuando es proporcionado con conciencia profesional de saber que se tiene una relación entre personas, más que enfermera-paciente; el fin que se persigue en esta relación es el confort tanto del paciente como de su familia.

Carper concluye con que es difícil distinguir si la enfermería es arte o ciencia; analizado primeramente el arte del cuidado, implica la utilización de todo el conocimiento empírico, y cuando se tiene este conocimiento se puede maximizar para crear el arte de enfermería. Sin embargo, para los profesionales del cuidado que realizan su práctica clínica y utilizan los patrones de conocimiento, la meta siempre será la del bienestar y confort de la persona.
En este sentido se comprende que se deja la pregunta para que cada profesional de enfermería la introyecte y analice de acuerdo con su propia perspectiva, si la enfermería es considerada $¿$ arte o ciencia, o bien ciencia o arte? Esperando que lo argumentado aclare o genere dudas que sean resueltas por su propia visión para la ciencia y arte del cuidado de enfermería.

\section{BIBLIOGRAFÍA}

1. Marriner T, Raile A. Modelos y Teorías en Enfermería. Sexta edición. España: Ed. Elsevier; 2007. pp. 3-8.

2. Bunge M. La Ciencia, su método y su Filosofía. Editorial Panamericana. México, D.F. 2012: pág: 6. Disponible en:http://moodle.unid.edu.mx/ dts_cursos_mdl/unida/AN/P1/P1S06/P106_Lectura.pdf Consultado 7 de enero de 2012.

3. González-Arnao V. Diccionario de la Real Academia de la Lengua Española, Madrid, España, pág: 302. Disponible en: http://books. google.com.mx/books?id=OanYapiW-OIC\&printsec $=$ frontcover\& $\mathrm{dq}=$ diccionario $+\mathrm{de}+\mathrm{la}+\mathrm{real}+\mathrm{academia}+\mathrm{espa} \% \mathrm{C} 3 \% \mathrm{~B} 1 \mathrm{ola} \& \mathrm{hl}=\mathrm{es}-$ 419\&sa=X\&ei=yjm3UbO9Buv-4AO1p4CwDw\&ved=0CDAQ6AEwAA

4. Abbagnano N. Diccionario de Filosofía. 4ta edición. México: Fondo de Cultura Económica; 2008. p. 158.

5. Blauberg L. Diccionario de Filosofía. México: Ediciones Quinto Sol; 2006. p. 45.

6. Op. Cit.Gonzalez-Arnao V. Diccionario de la Real Academia de la Lengua Española Diccionario de la Real Académia Española, pág: 653.

7. González-Rojo E. Diccionario Enciclopédico Práctico. Colombia: Grupo Editorial Norma; 1991. p. 138.

8. Gispert C. Enciclopedia Temática Universal Océano. Barcelona, España: Grupo Editorial Océano. México, D.F. p. 70.

9. Blauberg, Op. cit., p. 22.

10. Abbagnano, Op. cit., p. 104.

11. Marriner, Op. cit.

12. Riehl-Sisca J, Conceptual Models Ford Nursing Practice. $3^{\text {a }}$ edición. Editorial Norwalk Conn, Apleton 1999, pág: 502.

13. Kérouac S, Pepin J, Ducharme F, Duquette A, Mayor F. El Pensamiento Enfermero. Barcelona, España: Editorial Elsevier Masson; 2007. pp. 2-21.

14. Durán de Villalobos M. Enfermería: Desarrollo Teórico e Investigativo. Bogotá: Universidad Nacional de Colombia; 2001. pp. 44-45.

15. Kérouac, Op. cit., p. 12

16. Durán de Villalobos M. La ciencia, la ética y el arte a partir del conocimiento personal. Aquichan. 2005; 5 (1): 86-95.

17. Durán de Villalobos, Op. cit.

18. Carper B. Fundamental patterns of Knowing in nursing. In: Polifroni E, Welch M (eds.). Perspective on philosophy of science in nursing: an historical contemporary anthology. Lippincott Williams \& Wilkins. pp. 12-19. 